06,13

\title{
Создание и исследования структур металл-диэлектрик-полупроводник на основе сегнетоэлектрических пленок
}

\author{
(C) М.С. Афранасьев ${ }^{1}$, Д.А. Киселев ${ }^{1,2}$, С.А. Левашов ${ }^{1}$, А.А. Сивов ${ }^{1}$, Г.В. Чучева ${ }^{1, \text { ฯ }}$ \\ ${ }^{1}$ Фрязинский фрилиал Института радиотехники и электроники им. В.А. Котельникова РАН, \\ Фрязино, Россия \\ ${ }^{2}$ Национальный исследовательский технологический университет „МИСиС“, \\ Москва, Россия \\ ฯ E-mail: gvc@ms.ire.mssi.ru
}

Поступила в Редакцию 18 октября 2019 г.

В окончательной редакции 18 октября 2019 г.

Принята к публикации 23 октября 2019 г.

\begin{abstract}
В работе исследуется влияние температуры синтеза на микроструктуру и электрофизические свойства структур металл-диэлектрик-полупроводник на основе сегнетоэлектрических пленок состава $\mathrm{Ba}_{0.8} \mathrm{Sr}_{0.2} \mathrm{TiO}_{3}$ при формировании на кремниевые подложки р-типа с ориентацией [100]. Экспериментально установлено, что увеличение температуры синтеза приводит к улучшению диэлектрических и пьезоэлектрических свойств сегнетоэлектрических пленок. Показана температурная стабильность и устойчивость в поведении вольтфарадных характеристик МДП-структур от числа циклов переключения.
\end{abstract}

Ключевые слова: структуры металл-диэлектрик-полупроводник, сегнетоэлектрические пленки состава $\mathrm{Ba}_{0.8} \mathrm{Sr}_{0.2} \mathrm{TiO}_{3}$, микроструктура, сканирующая зондовая микроскопия, вольтфарадные характеристики, емкость, циклы переключения.

DOI: 10.21883/FTT.2020.03.49008.611

\section{1. Введение}

В последнее время перспективы создания нового поколения устройств обработки и хранения информации на основе структур металл-диэлектрик-полупроводник (МДП) связывают с использованием новых конструкционных как по составу, так и по структуре материалов. В качестве конструкционных материалов в МДП-структурах для устройств энергонезависимой памяти большой интерес представляют сегнетоэлектрические материалы [1].

Перспективным составом сегнетоэлектриков для применения в устройствах энергонезависимой памяти являются твердые растворы титаната бария-стронция $\left(\mathrm{Ba}_{1-x} \mathrm{Sr}_{x} \mathrm{TiO}_{3}\right)$. Состав $\mathrm{Ba}_{1-x} \mathrm{Sr}_{x} \mathrm{TiO}_{3}$ обладает сегнетоэлектрическими свойствами при комнатной температуре. Диэлектрическая постоянная тонких пленок $\mathrm{Ba}_{1-x} \mathrm{Sr}_{x} \mathrm{TiO}_{3}$ остается практически неизменной в широком интервале температур [2].

В работе изучается влияние температуры синтеза на микроструктуру и электрофизические свойства МДП-структур на основе пленок состава $\mathrm{Ba}_{0.8} \mathrm{Sr}_{0.2} \mathrm{TiO}_{3}$, сформированных на кремниевых подложках $p$-типа.

\section{2. Материалы и методики эксперимента}

Для исследований были изготовлены МДП-структуры, представляющие собой кремниевую подложку $p$-типа с ориентацией [100] и толщиной $300 \pm 10 \mu \mathrm{m}$, сегнетоэлектрическую пленку состава $\mathrm{Ba}_{0.8} \mathrm{Sr}_{0.2} \mathrm{TiO}_{3}$ (BST) и верхний электрод, выполненный из никеля. Сегнетоэлектрическая пленка толщиной $350 \pm 25 \mathrm{~nm}$ наносилась на кремниевую подложку методом высокочастотного распыления на установке Плазма-50СЭ (Россия). Конструкция установки и методика осаждения пленок приведены в $[3,4]$. Температура подложки в процессе синтеза составляла $560^{\circ} \mathrm{C}\left(\mathrm{BST}_{560}\right)$ и $620^{\circ} \mathrm{C}\left(\mathrm{BST}_{620}\right)$. Верхний электрод из никеля наносился на сегнетоэлектрическую пленку электронно-лучевым методом через теневую маску на установке A700QE/DI12000 (Германия). Для улучшения адгезии никеля к сегнетоэлектрической пленке структура в процессе напыления нагревалась до $100 \pm 5^{\circ} \mathrm{C}$. Скорость напыления никеля $2.0 \pm 0.1 \AA / \mathrm{s}$. Площадь электродов из никеля составляла $2.7 \pm 10^{-4} \mathrm{~cm}^{2}$, толщина $0.1 \mu \mathrm{m}$.

Рентгенодифракционное исследование показало, что для всех образцов наблюдалось параллельное расположение осей пленки и подложки в плоскости сопряжения ([100]BST $\|[100] p-\mathrm{Si})$.

Топография пленок BST получена в контактном режиме на сканирующем зондовом микроскопе MFP-3D SA (Asylum Research, США) с использованием кантилевера марки CSG10 (НТ-МДТ, Россия). Процессы локальной переполяризации и остаточные петли пьезоэлектрического гистерезиса получены в режиме силовой микроскопии пьезоотклика (СМП) с помощью кантилевера Asyelec-02 (Asylum Research, CША). Обработка и анализ изображений осуществлены в программе Gwyddion. 
Исследования электрофизических свойств полученных МДП-структур проведены на измерительном автоматизированном стенде [5] с использованием прецизионного измерителя LCR Agilent E4980A, портативного компьютера с доработанным программным обеспечением и специальной камеры, снабженной нагревательным столиком с термостабилизацией. Эффективная диэлектрическая проницаемость МДП-структур определена на основе измерений, проведённых по методике, изложенной в работах $[6,7]$.

\section{3. Результаты и обсуждение}

\section{1. Сканирующая зондовая микроскопия}

На рис. 1 представлены изображения топографии пленок BST, синтезированных при температурах 560 и $620^{\circ} \mathrm{C}$. Из полученных топографических изображений видно, что пленки сформированы из кристаллитов (зерен). Среднеквадратичная шероховатость поверхности $(R m s)$ составила 3.8 и $4.3 \mathrm{~nm}$ для $\mathrm{BST}_{560}$ и $\mathrm{BST}_{620}$ соответственно. Для количественной оценки размера зерен

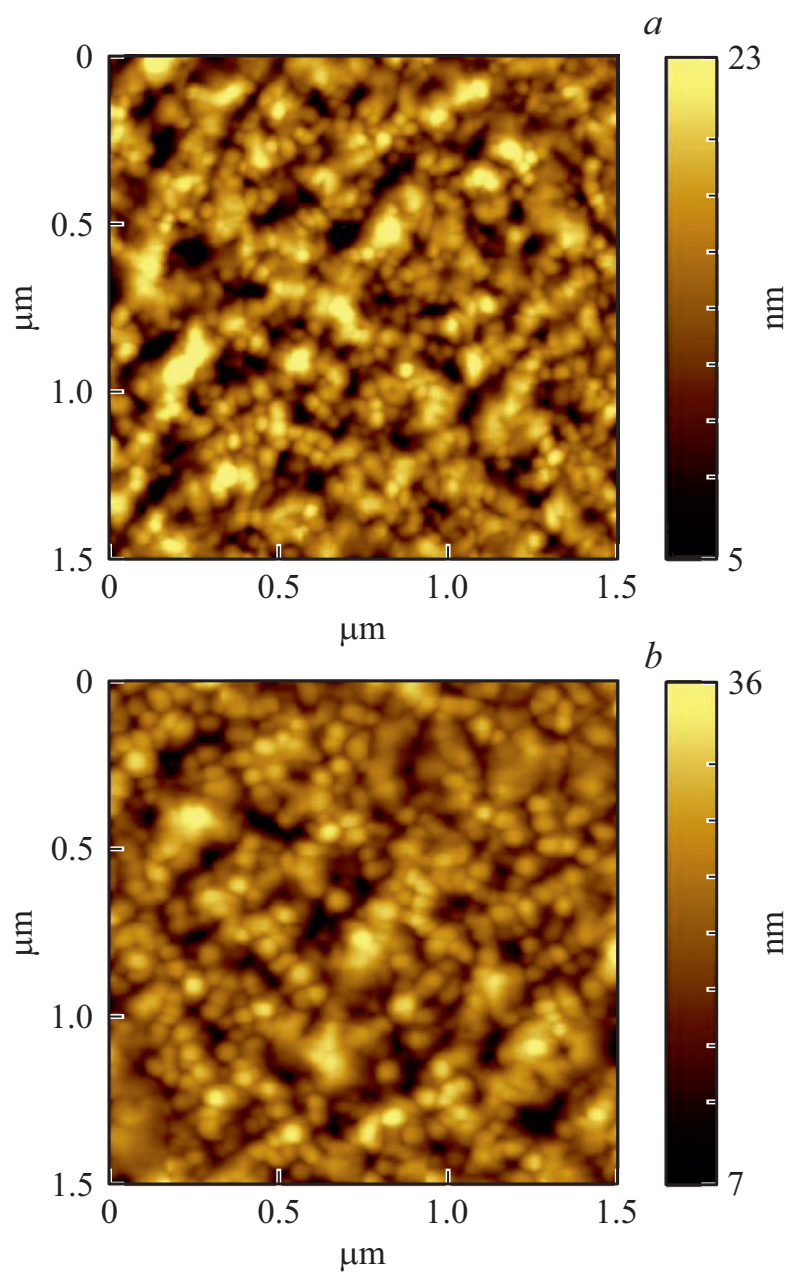

Рис. 1. Изображения поверхности пленок: $a-\mathrm{BST}_{560}$ и $b-\mathrm{BST}_{620}$.

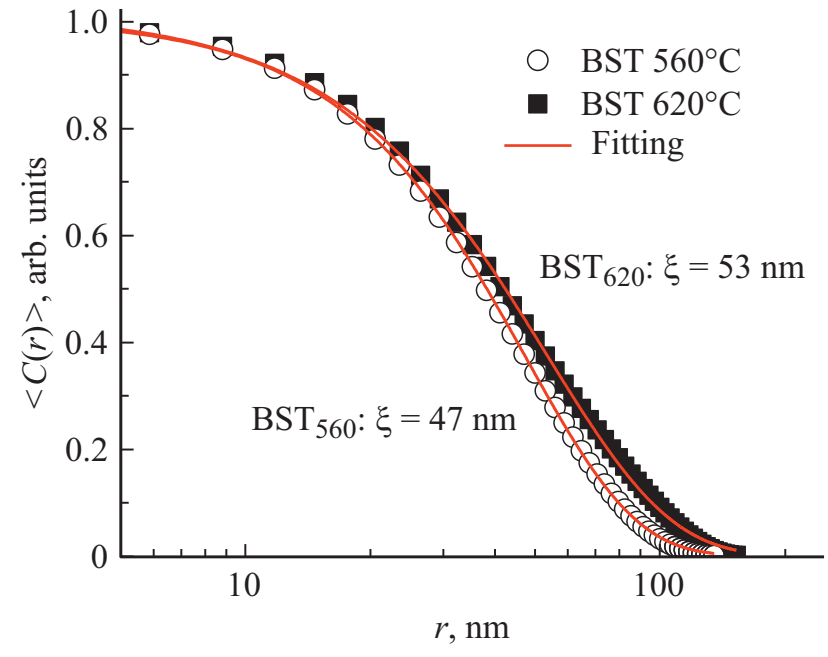

Рис. 2. Профили автокорреляционной функции (символы) и их аппроксимация (линии) для исследуемых пленок BST.

(корреляционной длины $\xi$ ) нами использовался метод автокорреляционной функции, подробно описанный в [8]. На рис. 2 показан результат аппроксимации корреляционной функции для определения среднего размера зерен в сегнетоэлектрических пленках. Расчеты показали, что для $\mathrm{BST}_{560}$ средний размер зерен составил $47 \mathrm{~nm}$, а при $\mathrm{BST}_{620} \xi=53 \mathrm{~nm}$.

В исследуемых МДП-структурах наблюдается локальное переключение поляризации под действием постоянного напряжения. На рис. 3, $a$ в качестве примера эффекта переполяризации представлен сигнал индуцированного пьезоотклика для пленки $\mathrm{BST}_{560}$. Индуцированные макродоменные области создавались путем сканирования пленки постоянным напряжением, подаваемым на проводящий кантилевер, который играл роль верхнего электрода. Таким образом, потенциалом создавались две заполяризованные области площадью $8 \times 8 \mu \mathrm{m}$ („,светлая область“ - поляризация при $+25 \mathrm{~V})$ и $4 \times 4 \mu \mathrm{m}$ („темная область“ - поляризация при $-25 \mathrm{~V})$. Полученные индуцированные домены стабильны в течение нескольких часов непрерывного сканирования.

Используя модуль спектроскопии переключения поляризации в режиме СМП, становится возможным получать остаточные петли пьезоэлектрического гистерезиса (рис. $3, b$ ) и тем самым исследовать эффект локального переключения поляризации в наномасштабе. Экспериментально установлено, что пленка BST $_{620}$ характеризуется большими значениями пьезоэлектрического коэффициента $\left(d_{33} \approx 147 \mathrm{pm} / \mathrm{V}\right.$ при $\left.+20 \mathrm{~V}\right)$ по сравнению с BST $_{560}$. Полученное нами значение эффективного пьезокоэффициента согласуется с теоретической работой [9], в которой использовалась нелинейная термодинамическая модель для расчета пьезоэлектрического коэффициента в эпитаксиальных пленках BST в зависимости от состава $(\mathrm{Ba} / \mathrm{Sr})$, деформаций несоответствия и температуры. Кроме того, для исследуемых 

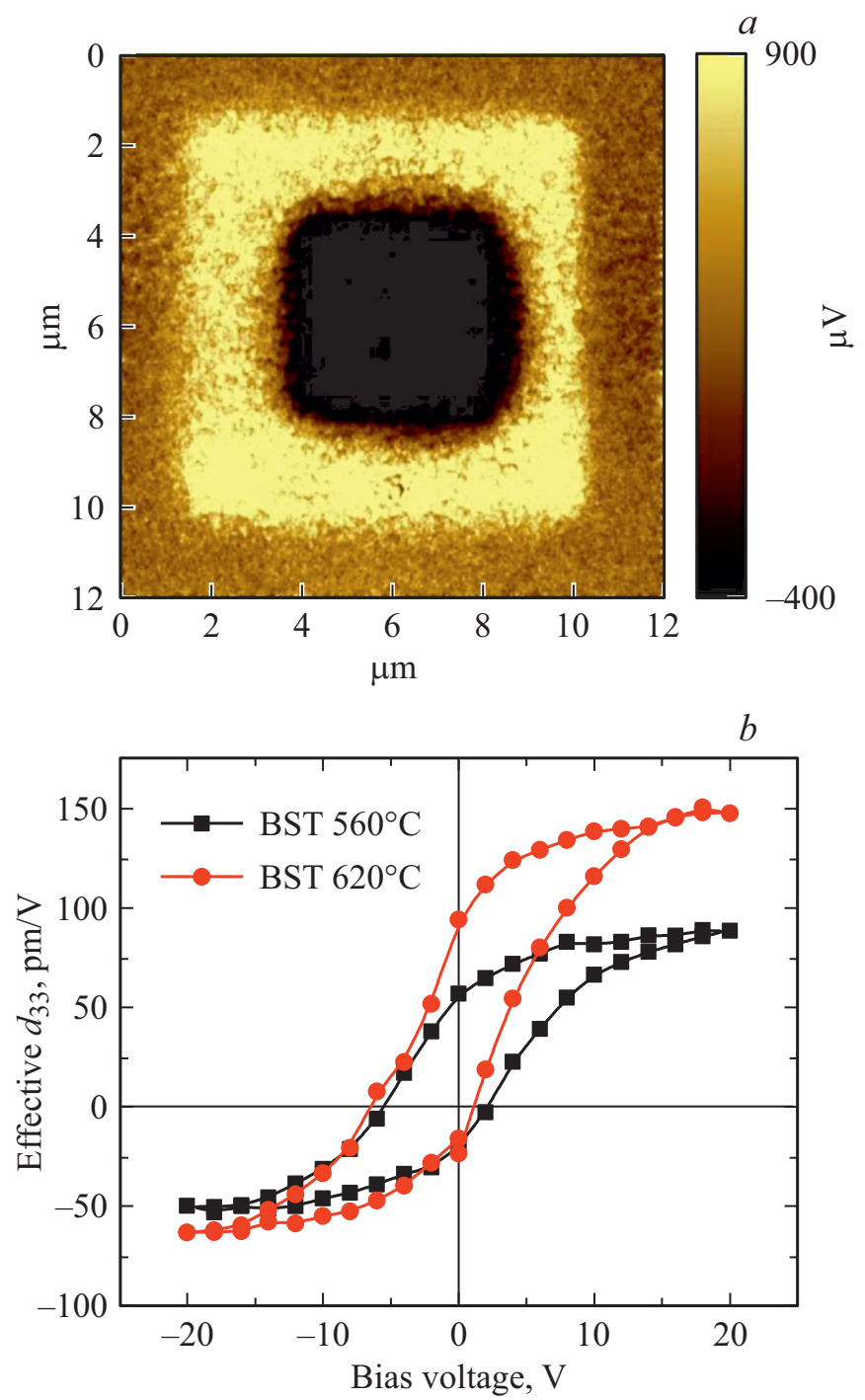

Рис. 3. Сигнал индуцированного пьезоотклика пленки $\mathrm{BST}_{560}(a)$, остаточные петли пьезоэлектрического гистерезиса для исследуемых пленок $(b)$.

пленок петли пьезоэлектрического гистерезиса имеют ассиметричный вид, что может быть связано с наличием встроенного электрического поля или с внутренним полем смещения, вызванным кислородными вакансиями и пространственным зарядом, в случае горизонтального смещения петли гистерезиса [10]. Вертикальное смещение обусловлено различными материалами кантилевера (Ti/Ir) и нижнего электрода (Si), что сказывается на контактной разности потенциала между ними [11].

\section{2. Электрофизические свойства}

На рис. 4 приведены вольтфарадные характеристики (ВФХ) МДП-структур BST $_{620}$ и BST $_{560}$, измеренные при комнатной температуре на частоте $100 \mathrm{kHz}$. На образец подавалось напряжение смещения $V_{g}$ от -20 до $+20 \mathrm{~V}$ (кривые 1,3) и обратно (кривая 2,4) с шагом $0.25 \mathrm{~V}$ и амплитудой измерительного сигнала $25 \mathrm{mV}$ со скоростью считывания данных 3 точки в секунду.

Зависимости емкости от напряжения смещения имеют форму петли (гистерезис). Ширина петли у обеих МДП-структур составляет $7 \pm 0.2 \mathrm{~V}$. Вертикальная ось симметрии петли структур сдвинута в сторону $V_{g} \simeq+2.6 \mathrm{~V}$. Сдвиг петли относительно точки $V_{g}=0 \mathrm{~V}$ может быть обусловлен присутствием в сегнетоэлектрической пленке внутреннего электрического поля, появление которого связано с различиями в структуре и зарядовом состоянии межфазной границы $\mathrm{Si} / \mathrm{BST}$.

У структуры BST $_{620}$ петля ВФХ имеет более симметричный вид (см. рис. 4, кривые 3,4 ), чем у структуры $\mathrm{BST}_{560}$ (см. рис. 4, кривые 1,2). Это позволяет говорить о более стабильном поведении структуры $\mathrm{BST}_{620}$.

Структуры BST $_{620}$ характеризуются более высокими значениями емкости по сравнению с аналогичными структурами $\mathrm{BST}_{560}$. Максимальные значения емкости наблюдались при $V_{g} \approx-20 \mathrm{~V}$ и составляли $63 \mathrm{pF}$ и $78 \mathrm{pF}$ для $\mathrm{BST}_{560}$ и $\mathrm{BST}_{620}$ соответственно.

На рис. 5 представлены измеренные при комнатной температуре и постоянном напряжении смещения $V_{g}=-20.0 \mathrm{~V}$ частотные зависимости емкости и тангенса угла диэлектрических потерь МДП-структур BST $_{620}$ и $\mathrm{BST}_{560}$. У обоих образцов с ростом частоты емкости падают. При этом структура BST $_{620}$ (кривая 2) демонстрирует более высокие значения емкости в диапазоне $1-1000 \mathrm{kHz}$, чем структура $\mathrm{BST}_{560}$ (кривая 1 ).

График частотной зависимости тангенса угла диэлектрических потерь для обоих объектов идентичен и имеет вид прямой, параллельной оси абсцисс в диапазоне $1-70 \mathrm{kHz}$, переходящий в резкий рост в диапазоне $70-1000 \mathrm{kHz}$. Значение тангенса угла диэлектрических потерь в среднем составляет для обеих кривых 0.02 в диапазоне частот $1-70 \mathrm{kHz}$ и возрастает до значения 0.17 в диапазоне $70-1000 \mathrm{kHz}$.

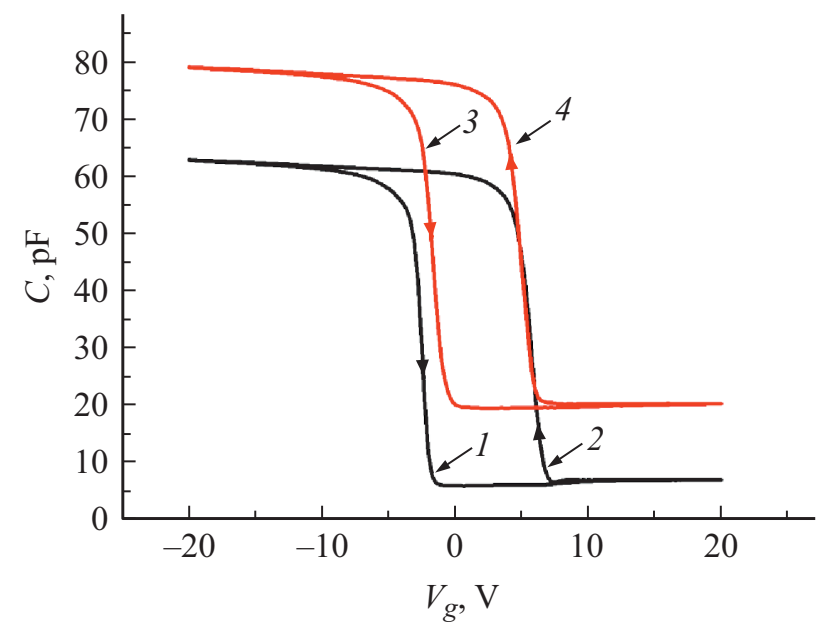

Рис. 4. Вольтфарадные характеристики МДП-структур BST $_{560}$ (кривая 1,2 ) и $\mathrm{BST}_{620}$ (кривая 3,4 ), измеренные при комнатной температуре на частоте $100 \mathrm{kHz}$. 


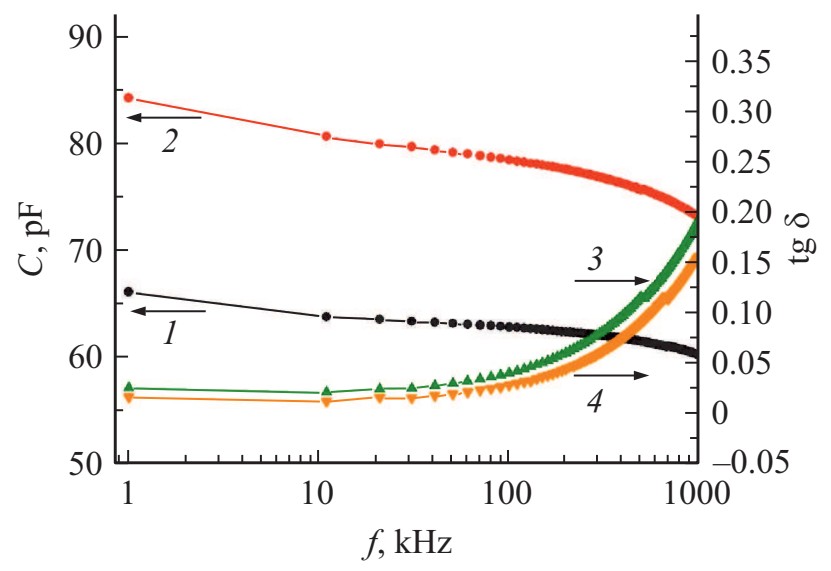

Рис. 5. Частотные зависимости емкости и тангенса угла диэлектрических потерь МДП-структур BST $_{560}$ (кривая 1,3) и BST $_{620}$ (кривая 2, 4), измеренные при постоянном напряжении смещения $V_{g}=-20 \mathrm{~V}$.

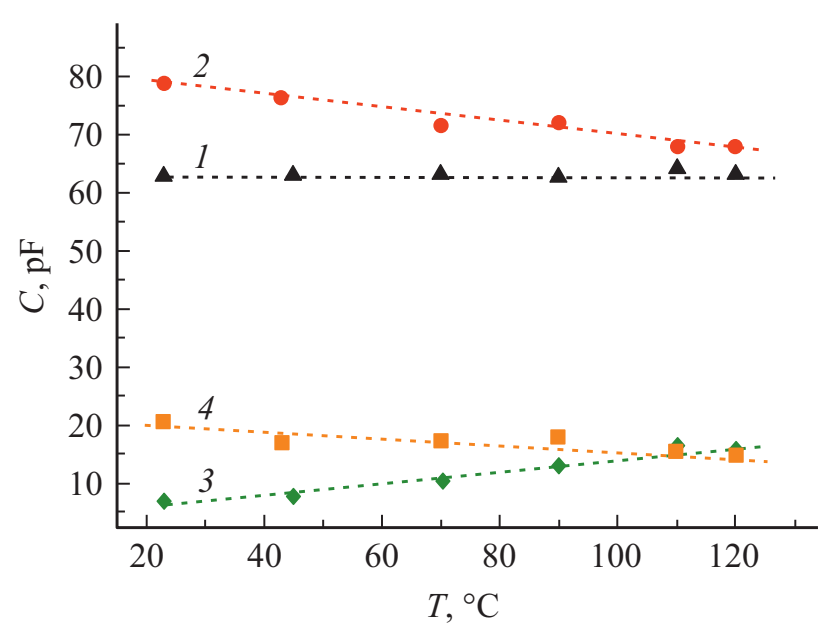

Pис. 6. Температурные зависимости емкости МДП-структур $\mathrm{BST}_{560}$ (кривая 1,3) и $\mathrm{BST}_{620}$ (кривая 2,4).

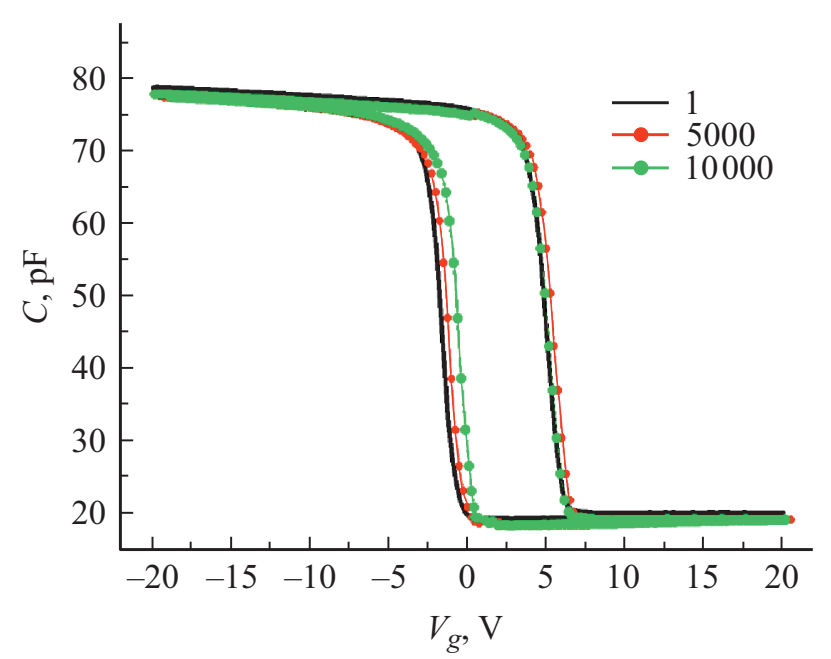

Рис. 7. Вольтфарадные характеристики структуры $\mathrm{BST}_{620}$ в зависимости от циклов переключения.
Из температурных зависимостей ВФХ МДП-структур на рис. 6 представлены температурные зависимости емкости образцов при $V_{g}=20 \mathrm{~V}$ (кривые 1,2) и $V_{g}=-20 \mathrm{~V}$ (кривые 3 и 4). Измерения ВФХ объектов проведены в диапазоне напряжений от -20 до $+20 \mathrm{~V}$ в интервале температур от 23 до $120^{\circ} \mathrm{C}$ на частоте $100 \mathrm{kHz}$.

При повышении температуры наблюдается незначительное уменьшение емкости у структуры BST $_{620}$ при $V_{g}=-20 \mathrm{~V}$. Напротив, емкость структуры $\mathrm{BST}_{560}$ не изменяется при $V_{g}=-20 \mathrm{~V}$ и несущественно возрастает при $V_{g}=+20 \mathrm{~V}$. Данное обстоятельство позволяет сделать вывод о том, что структура $\mathrm{BST}_{560}$ более термостабильна по сравнению со структурой $\mathrm{BST}_{620}$.

На рис. 7 приведены ВФХ структуры ВST $_{620}$ в зависимости от циклов переключений. На образец в течение $0.1 \mathrm{~s}$ подавалось напряжение $5 \mathrm{~V}$ с интервалом $0.1 \mathrm{~s}$. Проведено 10000 циклов (on/off). ВФХ структуры были измерены после 5000 и 10000 циклов переключений.

Установлено, что после 5000 циклов переключения структуры BST $_{620}$ значение емкости и форма кривой не меняется. После 10000 циклов переключения значение емкости также не меняется, но наблюдается незначительное сужение петли на $0.3 \mathrm{~V}$ в правую сторону.

\section{4. Заключение}

Проведенные исследования указали на влияние температуры синтеза тонких пленок BST на диэлектрические характеристики МДП-структур на их основе. Установлено, что синтезированные при температуре $620^{\circ} \mathrm{C}$ образцы обладают более высокими значениями емкости (и, соответственно, диэлектрической проницаемостью) по сравнению со структурами, полученными при $560^{\circ} \mathrm{C}$.

Результаты, полученные методом СМП, согласуются с диэлектрическими измерениями: с ростом температуры синтеза увеличиваются и диэлектрические, и пьезоэлектрические характеристики пленок BST 80/20.

Установлено, что ВФХ структуры ВST $_{620}$ после 5000 циклов переключения остаются неизменными.

\section{Финансирование работы}

Работа выполнена в рамках государственного задания и частично поддержана Российским фондом фундаментальных исследований (проекты № 18-29-11029, № 19-07-00271 и № 19-29-03042). Исследования методами сканирующей зондовой микроскопии выполнены на оборудовании ЦКП „Материаловедение и металлургия“ НИТУ „МИСиС“.

\section{Конфрликт интересов}

Авторы заявляют, что у них нет конфликта интересов. 


\section{Список литературы}

[1] К.А. Воротилов, В.М. Мухортов, А.С. Сигов. Интегрированные сегнетоэлектрические устройства / Под ред. А.С. Сигова. Энергоатомиздат, М. (2011). 175 с.

[2] В.М. Мухортов, Ю.И. Юзюк. Гетероструктуры на основе наноразмерных сегнетоэлектрических пленок: получение, свойства и применение. Изд-во ЮНЦ РАН, Ростов н/Д, (2008). $224 \mathrm{c}$.

[3] М.С. Афанасьев, М.С. Иванов. ФТТ 51, 1259 (2009).

[4] Д.А. Киселев, М.С. Афанасьев, С.А. Левашов, Г.В. Чучева. ФТТ 57, 6, 1134 (2015).

[5] Е.И. Гольдман, А.Г. Ждан, Г.В. Чучева. ПТЭ 6, 110 (1997).

[6] T. Hamano, D.J. Towner, B.W. Wessels. Appl.Phys. Lett. 83, 5274 (2003).

[7] P.M. Suherman, T.J. Jackson, Y.Y. Tse, I.P. Jones, R.I. Chakalova, M.J. Lancaster, A. Porch. J. Appl. Phys. 99, 104101-1 (2006).

[8] М.С. Афанасьев, Д.А. Киселев, С.А. Левашов, А.А. Сивов, Г.В. Чучева. ФТТ. 61, 1948 (2019).

[9] H. Khassaf, N. Khakpash, F. Sun, N.M. Sbrockey, G.S. Tompa, T.S. Kalkur, S.P. Alpay. Appl. Phys. Lett. 104, 20, 202902 (2014).

[10] Q. Lin, D.Y. Wang, Z.G. Chen, W.F. Liu, S. Li. ACS Appl. Mater. Interfaces. 7, 26301 (2015).

[11] P. Maksymovych, N. Balke, S. Jesse, M. Huijben, R. Ramesh, A.P. Baddorf, S.V. Kalinin. J. Mater. Sci. 44, 19, 5095 (2009).

Редактор К.В. Емщев 